\title{
Rate and Product Studies with 2-Methyl-2-Chloroadamantane under Solvolytic Conditions
}

\author{
Young Hoon Lee, Mi Hye Seong, ${ }^{\dagger}$ Eun Sung Lee ${ }^{\dagger}$ Yong-Woo Lee, ${ }^{\dagger}$ Hoshik Won, ${ }^{\dagger}$ Jin Burm Kyong ${ }^{\dagger, *}$ \\ and Dennis N. Kevill*
}

\author{
Department of Food and Biotechnology, Hanseo University, Seosan, ChungNam 356-706, Korea \\ ${ }^{\dagger}$ Department of Chemistry and Applied Chemistry, Hanyang University, Ansan-si, Gyeonggi-do 426-791, Korea \\ *E-mail: jbkyong@hanyang.ac.kr \\ ${ }^{\star}$ Department of Chemistry and Biochemistry, Northern Illinois University, DeKalb, Illinois 60115-2862, U.S.A. \\ Received January 27, 2010, Accepted March 2, 2010
}

\begin{abstract}
Reactions of 2-methyl-2-chloroadamantane (1) in a variety of pure and binary solvents have been studied at various temperatures and pressures up to $80 \mathrm{MPa}$. The sensitivity $(\mathrm{m})$ to changes in solvent ionizing power of the Grunwald-Winstein equation, and the activation volume $\left(\Delta \mathrm{V}^{\ddagger}\right)$ are calculated from the specific rates. An excellent linear relationship $(\mathrm{R}=0.997)$ for $1, \log \left(k / k_{0}\right)=0.80 Y_{C l}+0.11$, and the activation volume, $\Delta \mathrm{V}^{\ddagger}=-15.2 \sim-10.2 \mathrm{~mL} \cdot \mathrm{mol}^{-1}$ were observed. These values are similar to those for solvolyses of 1-adamantyl halides over the full range of solvents, suggesting that the unimolecular mechanism involving ion pairs is rate-determining. These observations are also compared with those previously reported for the corresponding 1-adamantyl derivatives and chloroformate esters.
\end{abstract}

Key Words: 2-Methyl-2-chloroadamantane, Grunwald-Winstein equation, Activation volume

\section{Introduction}

Almost 50 years ago, the volumes of activation $\Delta \mathrm{V}^{\ddagger}$ were shown to be a useful method for distinguishing between proposed mechanisms of certain reactions. ${ }^{1-3}$ The activation volume is determined from the pressure dependence of specific rates for the solvolysis of organic halides as defined in eqn. (1).

$$
\Delta \mathrm{V}^{\ddagger}=-\mathrm{RT}\left(\frac{d \ln k_{p}}{d P}\right) \mathrm{T}, \quad \ln k_{p}=\mathrm{a}+\mathrm{bP}
$$

Where $\Delta \mathrm{V}^{\star}$ may be considered as the sum of two components as shown in eqn. (2): an intrinsic part $\left(\Delta \mathrm{V}^{\ddagger}\right.$ intr. $)$, which represents the change in volume due to changes in bond lengths and angles, and a solvation part $\left(\Delta \mathrm{V}^{\ddagger}\right.$ solv. $)$, which represents the volume changes due to electrostriction and other effects acting on the surrounding solvent molecules during the activation process. $^{1(b), 4-6}$

$$
\Delta \mathrm{V}^{\ddagger}=\Delta \mathrm{V}_{\text {intr. }}^{\ddagger}+\Delta \mathrm{V}_{\text {solv }}^{\ddagger}
$$

In general, at high pressure, the unimolecular or $\mathrm{S}_{\mathrm{N}} 1$ reaction should have a positive activation volume and the bimolecular or $\mathrm{S}_{\mathrm{N}} 2$ reaction should have a large negative activation volume. The two mechanisms should, therefore, be easily distinguished by measuring the specific rates at high pressures.

There are two principal mechanisms; the kinetics and stereochemistry of the unimolecular or $\mathrm{S}_{\mathrm{N}} 1$ reactions such as the hydrolysis of $t-\mathrm{BuCl}$ in aqueous solution have been rationalized by the ion pair mechanism ${ }^{7}$ represented as

$$
\begin{aligned}
t-\mathrm{BuCl} \rightleftarrows t-\mathrm{Bu}^{+} \mathrm{Cl}^{-} & \rightleftarrows t-\mathrm{Bu}^{+} \| \mathrm{Cl}^{-} \rightleftarrows \\
t-\mathrm{Bu}^{+} \mathrm{Cl}^{-} & \stackrel{\mathrm{SOH}}{\text { fast }} t-\mathrm{BuOS}+\mathrm{H}^{+}+\mathrm{Cl}^{-}
\end{aligned}
$$

where $t-\mathrm{BuCl}$ is a reactant. $t-\mathrm{Bu}^{+} \mathrm{Cl}^{-}, t-\mathrm{Bu}^{+} \| \mathrm{Cl}^{-}, t-\mathrm{Bu}^{+}+\mathrm{Cl}^{-}$, and $t$ - BuOS are a tight ion pair, a solvent-separated ion pair, dissociated ions, and a product, respectively, which can all react with a nucleophile and then lead to nucleophilic substitution products. And another mechanism is the bimolecular or $\mathrm{S}_{\mathrm{N}} 2$ reactions for the solvolysis of organic halides, for example ${ }^{8}$

$$
\begin{aligned}
\mathrm{MeOTs}+\mathrm{SOH} & \longrightarrow\left[\begin{array}{c}
\mathrm{S}-\mathrm{O}_{\mathrm{\delta}}^{\delta^{+}--} \mathrm{Me}-\mathrm{OTs}^{\delta^{-}} \\
\mathrm{H}
\end{array}\right]^{+} \\
\underset{\mathrm{fast}}{\longrightarrow} & \mathrm{MeOS}+\mathrm{H}^{+}+\mathrm{OTs}^{-}
\end{aligned}
$$

In both reactions, there are two principal contributions to the activation volume. $^{1 \mathrm{~b}), 4-6}$ The first is the molecular contribution, which is positive if the molecule begins to fall apart in the transition state or negative if two molecules combine to form the transition state. The second is the electrostriction contribution, which always is negative if the halide develops a charge separation when it begins to fall apart, as it does for both mechanisms.

The Grunwald-Winstein equation has also been employed as a powerful mechanistic tool for solvolysis reactions [eqn. (3)]. ${ }^{9}$

$$
\log \left(k / k_{o}\right)=m Y_{\mathrm{x}}+c
$$

In eqn. $3, k$ and $k_{o}$ represent the specific rates of solvolysis in the solvent under consideration and in $80 \%$ ethanol, respectively; the parameter $m$ represents the sensitivity of the solvolysis towards changes in solvent ionizing power, $Y_{\mathrm{x}}$; and c represents a residual term. The equation (3) can be taken as one indicator of mechanism. Accordingly, determination of the $m$ values will be a valuable source of information concerning the structure of the transition state.

The Grunwald-Winstein equation [eqn. (3)] was proposed in 1948 for the correlation of solvolysis reactions proceeding 
by an ionization pathway, with rate-determining formation of a carbocation and its fast subsequent substitution or, when possible, elimination reaction. The original standard substrate, $t$-butyl chloride, has been replaced by 1 -adamantyl chloride ${ }^{10(c)}$ and either 1- or 2-adamantyl derivatives have been used to set up a series of $Y_{\mathrm{x}}$ scales for the $X$ leaving group. ${ }^{10(\mathrm{~b})}$ Since, with both substrates, a double bond would develop at the bridgehead, which is energetically disfavored (Bredt's Rule), ${ }^{11}$ only substitution product is observed.

One interesting substrate for consideration of this type is the formally closely related 2-methyl-2-chloroadamantane (1). ${ }^{11(b)}$ In the present study, we have investigated the additional specific rates for solvolyses of $\mathbf{1}$ in a variety of pure and binary solvents together with two specific rates previously observed by Bentley and their co-workers ${ }^{12}$ in $97 \%$ TFE and 97\% HFIP, and the influence of pressure on the solvolysis reaction and the product partitioning in hydroxylic solvents. The results have been also discussed the sensitivities $(m)$ toward change in solvent ionizing power $\left(Y_{\mathrm{Cl}}\right)$ and electrostriction contributions to solvent effect. In addition to the application of the simple Grunwald-Winstein equation to the specific rates, the influence of temperature on the specific rate allows enthalpies and entropies of activation to be calculated. Moreover, since both 1 and 1-adamantyl halides are tertiary aliphatic halides, mechanistic similarities would be expected. Accordingly, the current results have

Table 1. Specific rates of solvolysis of 2-methyl-2-chloroadamantane (1) in a variety of pure and mixed solvents at $25.0{ }^{\circ} \mathrm{C}$ and the $Y_{t-\mathrm{BuCl}}$ and $Y_{\mathrm{Cl}}$ values for the solvents

\begin{tabular}{cccc}
\hline Solvent $^{a}(\%)$ & $10^{5} k\left(\mathrm{~s}^{-1}\right)^{b}$ & $Y_{t-\mathrm{BuCl}}{ }^{c}$ & $Y_{\mathrm{Cl}}{ }^{d}$ \\
\hline $100 \mathrm{MeOH}$ & $1.34 \pm 0.01$ & -1.09 & -1.17 \\
$90 \mathrm{MeOH}$ & $8.60 \pm 0.04$ & -0.30 & -0.18 \\
$80 \mathrm{MeOH}$ & $40.5 \pm 1.0$ & 0.38 & 0.67 \\
$100 \mathrm{EtOH}$ & $0.133 \pm 0.020$ & -2.03 & -2.52 \\
$90 \mathrm{EtOH}$ & $1.33 \pm 0.05$ & -0.75 & -0.94 \\
$80 \mathrm{EtOH}$ & $6.85 \pm 0.13^{g}$ & 0.00 & 0.00 \\
$70 \mathrm{EtOH}$ & $25.2 \pm 0.5^{g}$ & 0.60 & 0.78 \\
$60 \mathrm{EtOH}$ & $87.3 \pm 2.4$ & 1.12 & 1.38 \\
$50 \mathrm{EtOH}$ & $343 \pm 14^{g}$ & 1.66 & 2.02 \\
$90 \mathrm{Acetone}$ & $0.144 \pm 0.037$ & -1.86 & -2.22 \\
$80 \mathrm{Acetone}$ & $1.48 \pm 0.01$ & -0.67 & -0.83 \\
$70 \mathrm{Acetone}$ & $8.46 \pm 0.16$ & 0.13 & 0.17 \\
$97 \mathrm{TFE}$ & $2.31 \times 10^{3 e}$ & 1.25 & 2.83 \\
$80 \mathrm{~T}-20 \mathrm{E}^{f}$ & $229 \pm 16$ & 1.15 & 1.89 \\
$60 \mathrm{~T}-40 \mathrm{E}^{f}$ & $26.5 \pm 0.4$ & -0.27 & 0.63 \\
$40 \mathrm{~T}-60 \mathrm{E}^{f}$ & $3.79 \pm 0.02$ & -0.87 & -0.48 \\
$30 \mathrm{~T}-70 \mathrm{E}^{f}$ & $1.64 \pm 0.02$ & -1.22 & - \\
$20 \mathrm{~T}-80 \mathrm{E}^{f}$ & $0.652 \pm 0.051$ & -1.52 & -1.42 \\
$97 \% \mathrm{HFIP}^{5}$ & $1.72 \times 10^{5 e}$ & 2.46 & 5.17 \\
\hline
\end{tabular}

${ }^{a}$ Volume/volume basis at $25.0{ }^{\circ} \mathrm{C}$, except for TFE- $\mathrm{H}_{2} \mathrm{O}, \mathrm{HFIP}-\mathrm{H}_{2} \mathrm{O}$ mixtures, which are on a weight/weight basis. ${ }^{b}$ The average of duplicate runs.

${ }^{c, d}$ Scales of solvent ionizing power based on the specific rates of solvolysis of $t$-butyl chloride ${ }^{13}$ and 1-adamantyl chloride, ${ }^{10}$ respectively. ${ }^{e}$ Values from ref. 12. ${ }^{f} \mathrm{~T}$-E are 2,2,2-trifluoroethanol-ethanol mixtures. ${ }^{g}$ Reference 14 reports the specific rates of $6.43 \times 10^{-5} \mathrm{sec}^{-1}$ in $80 \% \mathrm{EtOH} .24 .5 \times 10^{-5} \mathrm{sec}^{-1}$ in $70 \% \mathrm{EtOH}$, and $340 \times 10^{-5} \mathrm{sec}^{-1}$ in $50 \% \mathrm{EtOH}$, respectively. been compared with those previously reported for the corresponding 1-adamantyl derivatives and chloroformate esters.

\section{Results}

The specific rates of solvolysis of 2-methyl-2-chloroadamantane (1) were determined in 17 pure and binary solvents at $25.0{ }^{\circ} \mathrm{C}$. The solvents consisted of ethanol, methanol, binary mixtures of water with ethanol (EtOH), methanol (MeOH), acetone, and four binary mixtures of 2,2,2-trifluoroethanol (TFE) and ethanol (T-E). The specific rates of solvolysis are presented in Table 1, together with $Y_{t-\mathrm{BuCl}}$ and $Y_{\mathrm{Cl}}$ values.

For methanol, 90\%, 80\% MeOH, ethanol, 90\%, 80\% EtOH, and $20 \mathrm{~T}-80 \mathrm{E}, 60 \mathrm{~T}-40 \mathrm{E}$, specific rates of solvolysis of 1 were determined at two and three additional temperatures, and these values, together with calculated enthalpies and entropies of activation, are reported in Table 2.

The products from the solvolysis of $\mathbf{1}$ in ethanol, 90 - 50\% aqueous ethanol, and the full range of TFE-ethanol mixtures (Table 3 ), and in ethanol containing chloride and bromide ions (Table 3 footnote $e$ ) have been determined by gas chromatography (GC) with a flame ionization detector after completion of the reaction at $25.0{ }^{\circ} \mathrm{C}$ or $40.0{ }^{\circ} \mathrm{C}$.

The specific rates of solvolysis of 2-methyl-2-chloroadamantane (1) under various pressures were determined in 5 solvents

Table 2. Specific rates of solvolysis of 2-methyl-2-chloroadamantane (1) at various temperatures, and enthalpies $\left(\Delta \mathrm{H}^{\star}, \mathrm{kcal} \mathrm{mol}^{-1}\right)$ and entropies $\left(\Delta \mathrm{S}^{\ddagger}, \mathrm{cal} \mathrm{mol}^{-1} \mathrm{~K}^{-1}\right)$ of activation

\begin{tabular}{|c|c|c|c|c|}
\hline Solvent $^{a}(\%)$ & Temp. $\left({ }^{\circ} \mathrm{C}\right)$ & $10^{5} k\left(s^{-1}\right)^{b}$ & $\Delta \mathrm{H}^{*} 29{ }^{d}$ & $\Delta \mathrm{S}_{298}^{\dagger}{ }^{d}$ \\
\hline $100 \mathrm{MeOH}$ & $\begin{array}{l}25.0 \\
30.0 \\
35.0\end{array}$ & $\begin{array}{l}1.34 \pm 0.01 \\
2.72 \pm 0.03 \\
5.27 \pm 0.12\end{array}$ & $24.4 \pm 0.3$ & $1.0 \pm 0.8$ \\
\hline $90 \mathrm{MeOH}$ & $\begin{array}{l}25.0 \\
30.0 \\
35.0\end{array}$ & $\begin{array}{c}8.60 \pm 0.04 \\
16.6 \pm 0.1 \\
30.2 \pm 0.3\end{array}$ & $22.3 \pm 0.4$ & $-2.2 \pm 1.4$ \\
\hline $80 \mathrm{MeOH}$ & $\begin{array}{l}25.0 \\
30.0 \\
35.0\end{array}$ & $\begin{array}{c}40.5 \pm 1.0 \\
74.3 \pm 1.4 \\
133 \pm 4\end{array}$ & $21.1 \pm 0.05$ & $-3.2 \pm 0.2$ \\
\hline $100 \mathrm{EtOH}$ & $\begin{array}{l}25.0 \\
40.0 \\
45.0 \\
50.0\end{array}$ & $\begin{aligned} 0.133 & \pm 0.020 \\
0.970 & \pm 0.009 \\
1.85 & \pm 0.04 \\
3.37 & \pm 0.10\end{aligned}$ & $24.2 \pm 0.1$ & $-4.3 \pm 0.4$ \\
\hline $90 \mathrm{EtOH}$ & $\begin{array}{l}25.0 \\
30.0 \\
35.0\end{array}$ & $\begin{array}{l}1.33 \pm 0.05 \\
2.66 \pm 0.01 \\
5.03 \pm 0.06\end{array}$ & $23.7 \pm 0.4$ & $-1.4 \pm 1.2$ \\
\hline $80 \mathrm{EtOH}$ & $\begin{array}{l}25.0 \\
30.0 \\
35.0\end{array}$ & $\begin{array}{c}6.85 \pm 0.13 \\
13.0 \pm 0.2 \\
23.8 \pm 0.2\end{array}$ & $22.1 \pm 0.2$ & $-3.3 \pm 0.5$ \\
\hline $20 \mathrm{~T}-80 \mathrm{E}^{c}$ & $\begin{array}{l}25.0 \\
35.0 \\
40.0 \\
45.0\end{array}$ & $\begin{aligned} 0.652 & \pm 0.051 \\
2.42 & \pm 0.03 \\
4.56 & \pm 0.12 \\
8.32 & \pm 0.20\end{aligned}$ & $23.4 \pm 0.05$ & $-3.7 \pm 0.2$ \\
\hline $60 \mathrm{~T}-40 \mathrm{E}^{c}$ & $\begin{array}{l}20.0 \\
25.0 \\
35.0\end{array}$ & $\begin{array}{l}14.3 \pm 0.2 \\
26.5 \pm 0.4 \\
85.4 \pm 1.2\end{array}$ & $20.8 \pm 0.01$ & $-5.2 \pm 0.1$ \\
\hline
\end{tabular}

${ }^{a, b, c}$ See Table 1. ${ }^{d} \mathrm{With}$ associated standard error. 
Table 3. Percentages of products in the solvolysis of $1.08 \times 10^{-3} \mathrm{~mol} \mathrm{dm}^{-3}$ 2-methyl-2-chloroadamantane (1) in various hydroxylic solvents at $25.0{ }^{\circ} \mathrm{C}$

\begin{tabular}{|c|c|c|c|c|c|}
\hline Solvent ${ }^{a}(\%)$ & $Y_{\mathrm{Cl}}^{b}$ & Olefin $^{c}(3.18)^{d}$ & 2-Me-2-AdOEt $(7.58)^{d}$ & 2-Me-2-AdOTFE (8.22) ${ }^{d}$ & 2-Me-2-AdOH $(25.3)^{d}$ \\
\hline $100 \mathrm{EtOH}$ & -2.52 & 57.6 & $42.4^{f}$ & & - \\
\hline $90 \mathrm{EtOH}$ & -0.94 & 45.4 & 27.2 & & 27.4 \\
\hline $80 \mathrm{EtOH}$ & 0.00 & 33.8 & 20.3 & & 45.9 \\
\hline $70 \mathrm{EtOH}$ & 0.78 & 25.4 & 15.4 & & 59.2 \\
\hline $60 \mathrm{EtOH}$ & 1.38 & 18.5 & 11.8 & & 69.7 \\
\hline $50 \mathrm{EtOH}$ & 2.02 & 13.9 & 9.10 & & 77.0 \\
\hline $80 \mathrm{~T}-20 \mathrm{E}^{e}$ & 1.89 & 16.9 & 21.3 & 61.8 & \\
\hline $60 \mathrm{~T}-40 \mathrm{E}^{e}$ & 0.63 & 32.7 & 30.3 & 37.0 & \\
\hline $40 \mathrm{~T}-60 \mathrm{E}^{e}$ & -0.48 & 42.9 & 38.5 & 18.6 & \\
\hline $20 \mathrm{~T}-80 \mathrm{E}^{e}$ & -1.42 & 52.5 & 41.3 & 6.20 & \\
\hline
\end{tabular}

${ }^{a, e}$ See Table 1. ${ }^{b}$ Values from ref. $10 .{ }^{c}$ Olefin represents 2-methyleneadamantane. ${ }^{d}$ Retention time (min) under the GC conditions. ${ }^{f}$ In the presence of 0.00 , $0.01,0.02,0.04$, and $0.08 \mathrm{~mol} \mathrm{dm}^{-3} \mathrm{Et}_{4} \mathrm{NCl}$ at $40.0^{\circ} \mathrm{C}$, the values increase from 46.5 to $48.7,51.1,51.3$, and $51.4 \%$, and for $\mathrm{Et}_{4} \mathrm{NBr}$, from 46.6 to 46.9 , $48.4,51.2$, and $54.7 \%$, respectively.

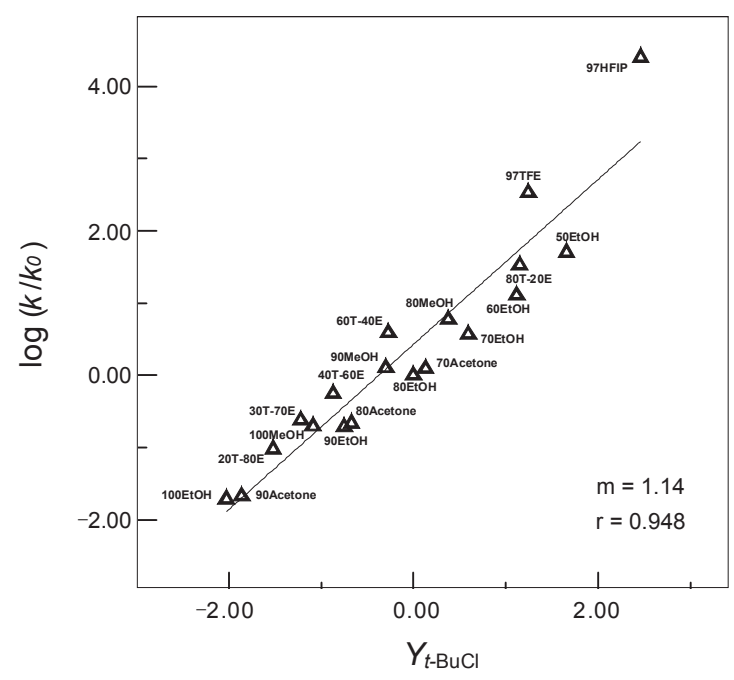

Figure 1. Plot of $\log \left(k / k_{o}\right)$ for solvolyses of 2-methyl-2-chloroadamantane (1) against tert-butyl chloride $\left(2, Y_{t-\mathrm{BuCl}}\right)$.

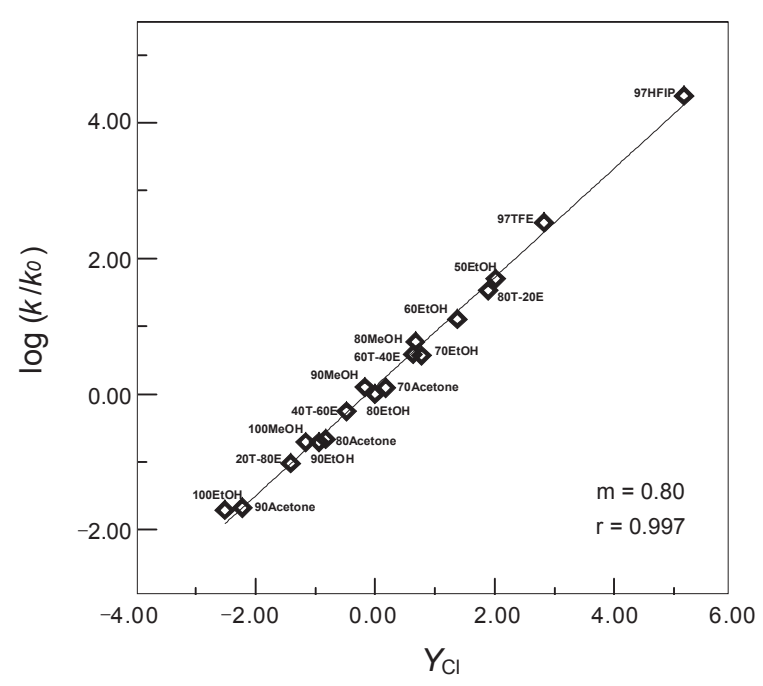

Figure 2. Plot of $\log \left(k / k_{o}\right)$ for solvolyses of 2-methyl-2-chloroadamantane (1) against 1-adamantyl chloride $\left(\mathbf{3}, Y_{\mathrm{Cl}}\right)$. at $25.0{ }^{\circ} \mathrm{C}$. The solvents consisted of methanol, binary mixtures of water with $\mathrm{EtOH}$ and $\mathrm{MeOH}$, and a binary mixture of TFE and ethanol (T-E). The specific rates of solvolysis are presented in Table 4 , together with $\Delta \mathrm{V}^{\ddagger}$ values.

\section{Discussion}

Solvolyses proceeding by ionization, without nucleophilic assistance, follow the simple Grunwald-Winstein (G-W) equation as the solvent is varied [eqn. (3)]. Figures 1 and 2 show the plots of the logarithms of specific rates for solvolyses of $\mathbf{1}$ against $Y_{t-\mathrm{BuCl}}$ and $Y_{\mathrm{Cl}}$, respectively. The high ionization power and relatively low nucleophilicity, 97\% TFE and 97\% HFIP in Figure 1 deviate markedly from the correlation line for the full range of solvents ( 0.948 for the correlation coefficient). Deviation of a plot of $\log \left(k / k_{o}\right)$ for 1 against $\log \left(k / k_{o}\right)_{t-\mathrm{BuCl}}(\mathbf{2}$, $\left.Y_{t-\mathrm{BuCl}}\right)$ in Figure 1 can be explained by nucleophilic solvent assistance in the tert-butyl chloride; it has been proposed that the solvolysis of tert-butyl chloride involves a nucleophilic component, although other workers ${ }^{10(\mathrm{a}),(\mathrm{c})}$ have suggested that the effects observed are related to electrophilic but not nucleophilic influences. But an plot of $\log \left(k / k_{o}\right)$ for 1 against $\log$ $\left(k / k_{o}\right)_{1-\mathrm{AdCl}}\left(3, Y_{\mathrm{Cl}}\right)$ for all of the solvents studied shows a good linear correlation with values of $0.80 \pm 0.02$ for $m$ and 0.997 for the correlation coefficient (Figure 2). This strongly suggests that solvolyses of $\mathbf{1}$ and $\mathbf{3}$ are proceeding through the same mechanism, presumably the unimolecular mechanism involving ion pairs. ${ }^{12,14}$

Activation parameter values for solvolyses of $\mathbf{1}$ in seven solvents are tabulated in Table 2. These values in Table 2 are consistent with the finding by Bentley et al. ${ }^{10(\mathrm{c}), 15}$ of similar activation parameters for the solvolyses of 1-adamantyl chloride and 2-adamantyl tosylate. Small negative or positive entropies of activation, in the range of 1.0 to $-5.2 \mathrm{cal} \mathrm{mol}^{-1} \mathrm{~K}^{-1}$, are consistent with the unimolecular nature (ionization reaction) of the proposed rate-determining step.

The reaction of $\mathbf{1}$ yields the products of elimination and solvolytic substitution (Table 3); 14\% 58\% 2-methyleneadamantane (olefin), 12\% 42\% 2-methyl-2-adamantyl ethyl 
Table 4. Specific rates of solvolysis of 2-methyl-2-chloroadamantane (1) in a variety of pure and mixed solvents at $25.0^{\circ} \mathrm{C}$ under various pressures

\begin{tabular}{|c|c|c|c|c|c|}
\hline \multirow{2}{*}{ Solvent $^{a}(\%)$} & \multicolumn{4}{|c|}{$10^{5} k\left(\mathrm{~s}^{-1}\right)^{b}$} & \multirow{2}{*}{$-\Delta \mathrm{V}^{\ddagger}\left(\mathrm{mL} \cdot \mathrm{mol}^{-1}\right)$} \\
\hline & $0.1 \mathrm{MPa}$ & $20 \mathrm{MPa}$ & $50 \mathrm{MPa}$ & $80 \mathrm{MPa}$ & \\
\hline $100 \mathrm{MeOH}$ & $1.34 \pm 0.01$ & $1.69 \pm 0.04$ & $1.92 \pm 0.01$ & $2.26 \pm 0.15$ & 15.2 \\
\hline $90 \mathrm{MeOH}$ & $8.60 \pm 0.04$ & $9.92 \pm 0.11$ & $11.7 \pm 0.3$ & $13.2 \pm 0.2$ & 13.3 \\
\hline $90 \mathrm{EtOH}$ & $1.33 \pm 0.05$ & $1.53 \pm 0.01$ & $1.71 \pm 0.07$ & $1.86 \pm 0.04$ & 10.2 \\
\hline $80 \mathrm{EtOH}^{c}$ & $6.85 \pm 0.13$ & $7.50 \pm 0.10$ & $8.63 \pm 0.16$ & $9.93 \pm 0.12$ & 11.5 \\
\hline $60 \mathrm{~T}-40 \mathrm{E}^{d}$ & $26.5 \pm 0.4$ & $31.1 \pm 0.2$ & $35.2 \pm 0.4$ & $40.8 \pm 0.6$ & 13.2 \\
\hline
\end{tabular}

${ }^{a, b, d}$ See Table 1. ${ }^{c}$ Percentages of products in the solvolysis of $1.08 \times 10^{-3} \mathrm{~mol} \mathrm{dm}^{-3}$ 2-methyl-2-chloroadamantane at $25.0{ }^{\circ} \mathrm{C}$ are $31 \% 2$-methyleneadamantane (olefin), 23\% 2-methyl-2-adamantyl ethyl ether and 46\% 2-methyl-2-adamantanol in $50 \mathrm{MPa}$, and 29\% 2-methyleneadamantane (olefin), 24\% 2-methyl-2-adamantyl ethyl ether and 47\% 2-methyl-2- adamantanol in $150 \mathrm{MPa}$, respectively.

ether (or 21\% 41\% 2-methyl-2-adamantyl (2,2,2-trifluoro) ethyl ether), and 27\% 77\% 2-methyl-2-adamantanol, respectively. These values are very similar to those previously observed by Shiner ${ }^{14}$ and Bentley ${ }^{12}$ and their co-worker. As expected, the amount of 2-methyl-2-adamantanol (2-Me-2-AdOH) increased with increasing water content of the solvent, and in aqueous ethanol and TFE-ethanol mixtures the amount of 2-methyleneadamantane (olefin) decreased with increasing the sol-

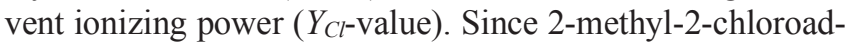
amantane (1) is sterically incapable of undergoing backside solvolytic displacement, the substitution product must form by front side displacement, probably involving solvent-separated ion pair. ${ }^{16}$

Added chloride and bromide ions (tetraethylammonium chloride and tetraethylammonium bromide) slightly divert the product away from olefin and toward the ethyl ether (Table 3 footnote $e$ ). The percentage of 2-methyleneadamantane (olefin) falls slightly as salt concentration or pressure (Table 4 footnote $c$ ) is increased. These effects can be rationalized in terms

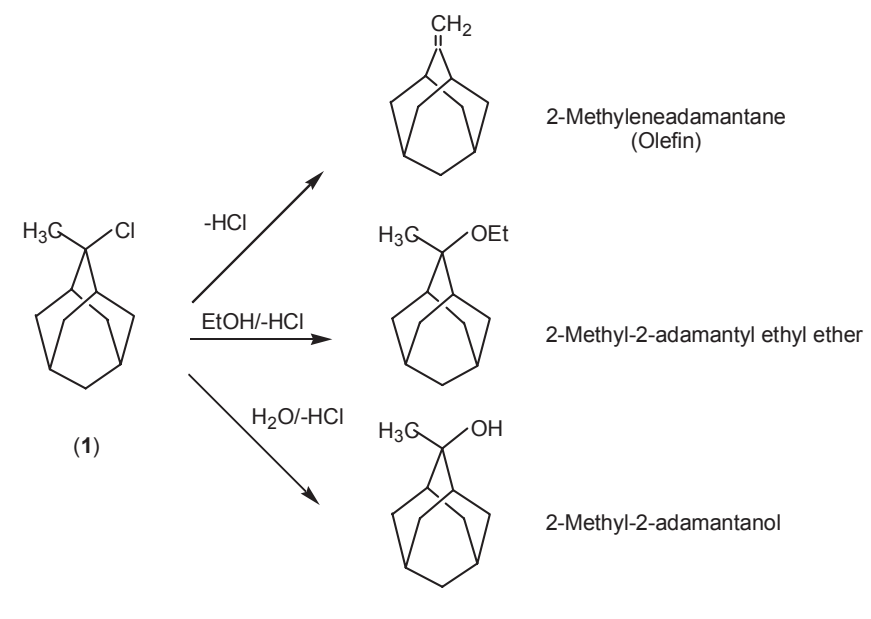

Scheme 1 of increase in solvent ionizing power upon addition of polar to relatively low ionizing power solvents. Although solvent ionizing power is not indicated in the rate-determining step, the low ionizing solvents, by their competition with the chloride ion, may promote chloride ion-induced elimination. Based on our data and previous studies, ${ }^{12,14}$ all of the products of solvolysis of 2-methyl-2-chloroadamantane (1) in ethanol-water mixtures are outlined in Scheme 1.

The high $m$-value (0.80) and product studies for the solvolysis of 1 are also consistent with an ionization pathway involving ion pairs. These results can be represented using the mechanism show in Scheme 2, where 2-Me-2-AdCl is a reactant. 2-Me-2- $\mathrm{Ad}^{+} \mathrm{Cl}^{-}, 2-\mathrm{Me}-2-\mathrm{Ad}^{+} \| \mathrm{Cl}^{-}$, and 2-Me-2-AdOS are a tight ion pair, a solvent-separated ion pair, and a product, respectively. From product studies (Table 3), the rate-determining step for the solvolysis of $\mathbf{1}$ is the second step, which leads to the formation of solvent-separated ion pairs when solvents of high polarity are used. After the transition state is reached, other intermediates, such as tight ion pairs, may be form if the particular solvent (or solvents of low polarity) stabilized the tight ion pair. If they are formed, substitution may only occur from the tight ion pair. For all the ethanol-water solvents studied (Table 3), the reaction of 1 gives both substitution products (2-Me-2-AdOH and 2-Me-2-AdOEt) and the elimination product (olefin). Therefore, the substitution products must occur in a reaction step after the transition state since solvent insertion (solvent separated ion pair) between the ions must occur (Scheme 2).

The activation volumes $\left(\Delta \mathrm{V}^{*}=-15.2 \sim-10.2 \mathrm{~mL} \cdot \mathrm{mol}^{-1}\right)$ for the solvolysis of $\mathbf{1}$ in 5 solvents are all negative (Table 4). Negative values of $\Delta \mathrm{V}^{\ddagger}$ for solvolytic reactions are usually referred to as "electrostriction". These values represent that the contraction of the surrounding solvent due to the appearance of the partial charges is greater than the increase in volume caused by the lengthening of the carbon-chloride bond. We previously reported a comparison of solvents and pressure effects

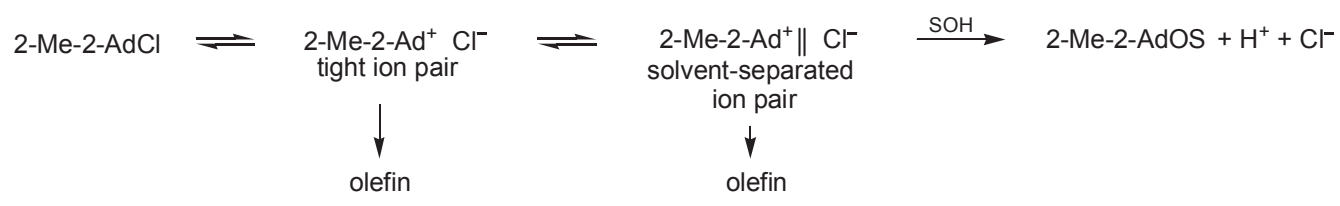

Scheme 2 
on the reactivity of the earlier studied substrates (1-adamantyl chloride, bromide, tosylate, fluoroformate, and methyl and phenyl chloroformates) in hydroxylic solvents. ${ }^{1(c), 17}$ For the solvolyses of 1-adamantyl halides at high pressures, the activation volumes of -15.4 to $-11.7 \mathrm{~mL} \cdot \mathrm{mol}^{-1}$ for solvolyses in several hydroxylic solvents were observed previously. ${ }^{1(\mathrm{c}), 17}$ These values were considered to be consistent with the ionization mechanism being rate determining. The values of $\Delta \mathrm{V}^{*}$ in the range of $-30.4 \mathrm{~mL} \cdot \mathrm{mol}^{-1}$ to $-24.6 \mathrm{~mL} \cdot \mathrm{mol}^{-1}$ for the solvolyses of haloformate esters have also been reported. ${ }^{1(\mathrm{c}), 17}$ These are general characteristics of the bimolecular mechanism; this will have a large negative activation volume because two molecules combine to form the transition state or the electrostriction of the solvent molecules.

The activation volume, $\Delta \mathrm{V}^{*}$ reflects part of the configurational changes in the transition state, while the activation entropy, $\Delta S^{\ddagger}$ reflects not only these spatial effects but also some dynamical or vibrational effects as well. Accordingly, the study of $\Delta \mathrm{V}^{*}$ against $\Delta \mathrm{S}^{\star}$ will provide a route to mechanistic deduction. ${ }^{1 \mathrm{~b})}$ To prove further the similarity between solvent effects upon the specific rates of solvolysis of $\mathbf{1}$ and alkyl halides or alkyl halogenoformate esters, we have carried out a direct comparison of the activation parameters for $\mathbf{1}$ against those for alkyl halides and alkyl halogenoformate esters. The relationship for $\Delta \mathrm{V}^{\ddagger}$ against $\Delta \mathrm{S}^{\ddagger}$ in Figure 3 can divide into two principal mechanisms for all the substrates, i.e., the so-called unimolecular mechanism postulated to represent ionization pathway and bimolecular mechanism believed to represent bond formation pathway. The activation values of -15.2 to $-10.2 \mathrm{~mL} \cdot \mathrm{mol}^{-1}$ for 2-methyl-2-chloroadamantane (1) in Figure 3 are similar groups to those for the solvolyses of several 1-adamantyl halides, ${ }^{1(c), 17}$ suggesting that the unimolecular mechanisms involving ion pairs are rate-determining.

Electrostriction is a phenomenon where a strong electrostatic interaction exerts between a tight ion pair or solvent-separated ion pair and the surrounding solvent molecules. Therefore, the degree of freedom of the solvent molecules is restricted, resulting in a decrease in the entropy of the system. In fact, re-

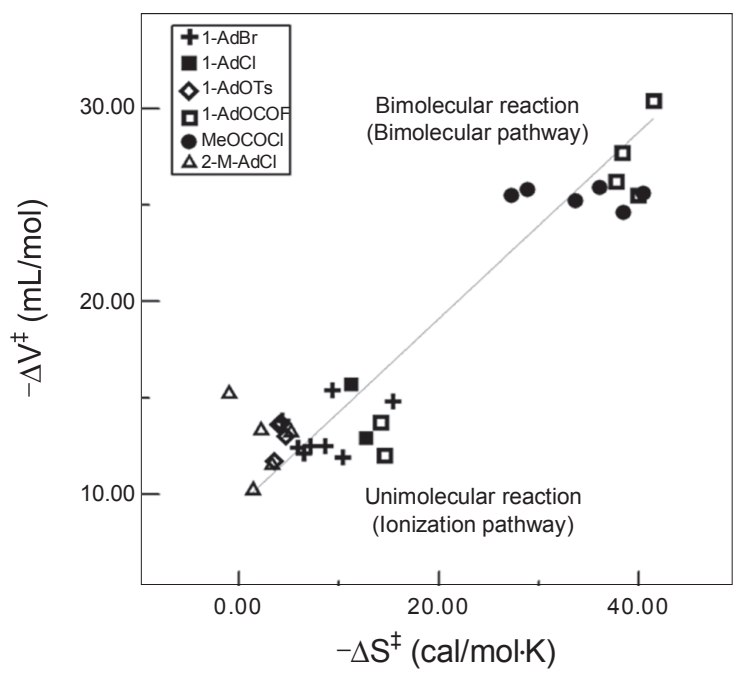

Figure 3. Correlation of $\Delta \mathrm{V}^{\ddagger}$ against $\Delta \mathrm{S}^{\ddagger}$ for the solvolyses of 1-adamantyl halides and haloformates esters. ${ }^{1(c)}$ actions which have large negative $\Delta \mathrm{V}^{\ddagger}$ values are known to be characterized by large negative $\Delta \mathrm{S}^{\star}$ values. ${ }^{18}$ Accordingly, one can anticipate the presence of a rough correlation between $\Delta \mathrm{V}^{*}$ and $\Delta \mathrm{S}^{*}$ (Figure 3 ). The fact that the correlation between these two activation parameters holds in the present reaction strongly supports the validity of the application of the electrostriction theory in the present mechanistic representation of the reaction.

\section{Conclusions}

The specific rates of solvolyses of 2-methyl-2-chloroadamantane (1) give a satisfactory simple Grunwald-Winstein correlation (eqn. 3) over the full range of solvents $(r=0.997)$. The $m$-value ( $m=0.80)$ obtained from the simple Grunwald-Winstein treatment of the specific rates of solvolyses of $\mathbf{1}$ is similar to those for the 1-adamantyl halides, which are believed to be solvolyzed through unimolecular mechanism, with the ionization step being rate determining.

The analyses of the activation parameters and product studies for the solvolyses of $\mathbf{1}$ show large positive values for the enthalpy of activation and small negative values for the entropy of activation, and both substitution products and the elimination product, suggesting that an unimolecular process involving ion pairs is rate-determining.

The activation values, $\Delta \mathrm{V}^{*}=-15.2 \sim-10.2 \mathrm{~mL} \cdot \mathrm{mol}^{-1}$ (Table 4) obtained in a comparison with the corresponding solvolysis of $\mathbf{1}$ are similar to those for solvolyses of 1-adamantyl halides $\left(\Delta \mathrm{V}^{\ddagger}=-15.4 \sim-11.7 \mathrm{~mL} \cdot \mathrm{mol}^{-1}\right)$ proceeding through ion pairs.

On the basis of these results, we have concluded that the solvolysis of 2-methyl-2-chloroadamantane (1) in a variety of pure and binary solvents proceeds via the ionization mechanism; namely, the solvolysis of $\mathbf{1}$ for all the solvents studied proceeds via a nucleophilically solvated solvent-separated ion pair (solvent insertion) intermediate, followed by the formation of the solvolysis products (Scheme 2) and by the constraction (electrostriction) of the surrounding solvent due to the appearance of the partial charges (substrate ions). Accordingly, determination of these values ( $m$ value and $\Delta \mathrm{V}^{*}$ value) will be a valuable source of information concerning the structure of the transition state for these solvolyses.

\section{Experimental}

2-Methyl-2-chloroadamantane (1) was prepared from 2methyl-2-adamantanol (Aldrich, 97\%) as previously studied. Recrystallization from hexane yielded pure $1, \operatorname{mp} 175-176{ }^{\circ} \mathrm{C}$ (lit. ${ }^{19} 176-176.5^{\circ} \mathrm{C}$ ). The solvents were purified as previously described. $^{20}$

The high pressure apparatus and kinetic runs for the specific rates as a function of pressure were as previously described. ${ }^{17}$ The kinetic measurements were made conductometrically using a Metrohm 665 (Swiss) instrument, with a cell constant of $0.915 \mathrm{~cm}^{-1}$. All runs were performed in duplicate with at least 70 readings taken at appropriate intervals over three half-lives and infinity readings taken after ten half-lives. The rates of production of hydrochloric acid were followed for solvolyses in methanol $(\mathrm{MeOH})$, ethanol (EtOH), aqueous organic mixtures, 2,2,2-trifluoroethanol (TFE)- $\mathrm{H}_{2} \mathrm{O}$ mixtures, TFE-EtOH 
mixtures, and 1,1,1,3,3,3-hexafluoro-2-propanol (HFIP)- $\mathrm{H}_{2} \mathrm{O}$ mixtures. The substrate concentration was about $1.01 \times 10^{-3} \sim$ $1.26 \times 10^{-3} \mathrm{~mol} \mathrm{dm}^{-3}$.

The products from the reactions of $\mathbf{1}$ under solvolytic conditions were analyzed after ten half-lives by gas chromatography (Schimazu GC-9A) using a 2.1-m glass column containing 10\% Carbowax $20 \mathrm{M}$ on Chromosorb WAW 80/100 with an injection temperature of $120^{\circ} \mathrm{C}$ and column temperature of $80^{\circ} \mathrm{C}$. Nitrogen was used as the carrier gas and a flame ionization detector was employed. The retention times $(\mathrm{min})$ at $80{ }^{\circ} \mathrm{C}$ were as follows: olefin (2-methyleneadamantane), 3.18; 2-methyl-2adamantyl ethyl ether, 7.58; 2-methyl-2-adamantyl (2,2,2-trifluoro)ethyl ether, 8.22; and 2-methyl-2-adamantanol, 25.3. Experiments were also carried out using $1.08 \times 10^{-3} \mathrm{~mol} \mathrm{dm}^{-3}$ substrate in ethanol at $40.0{ }^{\circ} \mathrm{C}$ in the presence of up to 0.08 $\mathrm{mol} \mathrm{dm}{ }^{-3}$ tetraethylammonium chloride and tetraethylammonium bromide.

Acknowledgments. This paper was supported by Korean Council for University Education, grant funded by Korean Government (MOEHRD) for 2008 Domestic Faculty Exchange.

\section{References}

1. (a) Eldik, R. V.; Asano, T.; Noble, J. L. Chem. Rev. 1978, 78, 407. (b) Eldik, R. V.; Asano, T.; Noble, J. L. Chem. Rev. 1989, 89, 549.

(c) Drljaca, A.; Hubbard, C. D.; Eldik, R. V.; Asano, T.; Basilevsky, M. V.; Noble, J. L. Chem. Rev. 1998, 98, 2167.

2. Koskikallio, J.; Whalley, E. Trans. Faraday Soc. 1959, 55, 809.

3. Whalley, E. Adv. Phys. Org. Chem. 1964, $2,93$.

4. Noble, J. L.; Kelm, H. Angew. Chem. Int. Ed. Engl. 1980, 19, 841.

5. Hamann, S. D. Rev. Phys. Chem. Jpn. 1980, 50, 147.

6. Schmidt, R. J. Phys. Chem. A 1998, 102, 9082.
7. (a) For reviews, see: March, J. Advanced Organic Chemistry, 4th ed.; John Wiley \& Sons: New York, 1992; pp 293-500. (b) Okuno, Y. J. Phys. Chem. A 1999, 103, 190.

8. Yamagami, C.; Sera, A.; Maruyama, K. Bull. Chem. Soc. Jpn. 1974, 47, 881 .

9. Grunwald, E.; Winstein, S. J. Am. Chem. Soc. 1949, 70, 846.

10. (a) Bentley, T. W.; Llewellyn, G. Prog. Phys. Org. Chem. 1990, 17, 121. (b) Kevill, D. N.; D’Souza, M. J. J. Chem. Res. Synop. 1993, 174. (c) Bentley, T. W.; Cater, G. E. J. Am. Chem. Soc. 1982, 104, 5741. (d) Koo, I. S.; Bentley, T. W.; Kang, D. H.; Lee, I. J. Chem. Soc., Perkin Trans. 2 1991, 296. (e) Lomas, J. S.; D’Souza, M. J.; Kevill, D. N. J. Am. Chem. Soc. 1995, 117, 5891.

11. (a) Schleyer, P. von R.; Nicholas, R. D. J. Am. Chem. Soc. 1961, 83, 2700. (b) McManus, S. P.; Somani, S.; Harris, J. M.; McGill, R. A. J. Org. Soc. 2004, 69, 8865.

12. (a) Bentley, T. W.; Bowen, C. T.; Parker, W.; Watt, C. I. F. J. Am. Chem. Soc. 1979, 101, 2486. (b) Bentley, T. W.; Bowen, C. T.; Parker, W.; Watt, C. I. F. J. Chem. Soc., Perkin Trans. 2 1980, 1244.

13. (a) Wells, P. R. Chem. Rev. 1963, 63, 171. (b) Kaspi, J.; Rappoport, Z. J. Am. Chem. Soc. 1980, 102, 3829. (c) McManus, S. P.; Safavy, A. J. Org. Chem. 1986, 51, 3532. (d) Fainberg, A. H.; Winstein, S. J. J. Am. Chem. Soc. 1956, 78, 2770.

14. Fisher, R. D.; Seib, R. C. Shiner, V. J.; Szele, J. I.; Tomic, M.; Sunko, D. E. J. Am. Chem. Soc. 1975, 97, 2408.

15. Bentley, T. W.; Bowen, C. T.; Morten, D. H.; Schleyer, P.v. R. J. Am. Chem. Soc. 1981, 103, 5466.

16. Adcock, W.; Trout, N. A.; Vercoe, D.; Taylor, D. K.; Shiner, V. J., Jr.; Sorensen, T. S. J. Org. Chem. 2003, 68, 5399.

17. (a) Kwun, O. C.; Kim, J. R.; Kyong, J. B.; Lee, Y. H.; Kim, J. C. J. Korean Chem. Soc. 1996, 40, 327. (b) Kim, D. K.; Kyong, J. B. J. Korean Chem. Soc. 2001, 45, 603.

18. Glasstone, S.; Laidler, K. J.; Eyring, H. In The Theory of Rate Processes; McGraw-Hill: N. Y. and London, 1941.

19. Kovacevic, D.; Majerski, Z.; Borcic, S.; Sunko, D. E. Tetrahedron 1972, 28, 2469.

20. Seong, M. H.; Kyong, J. B.; Kim, D. K.; Kevill, D. N. Bull. Korean Chem. Soc. 2008, 29, 1747. 